\title{
A Vector Error Correction Model Approach to Investigate the Causal Relationship among Energy Consumption, Real GDP, and Industry Value Added of Bangladesh
}

\author{
Moumita Datta Gupta, \\ Md. Mahfuzur Rahman, \\ Mohammad Mastak Al Amin, \\ BRAC University, Bangladesh
}

\begin{abstract}
The paper focuses on investigating the casual relationship among Energy Consumption, Real GDP, and Industry Value Added of Bangladesh using the World Bank Development Indicators data set. The Granger causality approach has been applied to identify the short-run causality direction for all possible pairs of dynamic variables of the study. Results from the approach indicate the unidirectional short run causal relationship from Real GDP to Energy Consumption, while another unidirectional short-run causality has been found from Industry Value Added to Real GDP. The concept of cointegration and Vector Error Correction Model (VECM) are employed to find the long-run relationships among the variables. Our results show the existence of long run relationship between each pair of variables. Furthermore, the Variance Decomposition (VDC) techniques and Impulse Response Function (IRF) was also used to measure the extent/degree of dynamic properties of the variables. Bangladesh has an emerging economy with limited energy resources. Here, the evidence from our study would help policymakers in setting the appropriate energy consumption policies that will enhance and sustain economic growth for the welfare/development of this country.
\end{abstract}

Keywords: Granger Causality, Cointegration, VECM, VDC, IRF, Industry Value Added

\section{Introduction}

Energy is one of the basic production inputs and is very important in terms of socioeconomic, fiscal, and strategic issues for countries (Cutler, 2006; Amin et al., 2017). These features of energy distinguish it from other 
markets and also force the countries to develop policies in this field. Government can use different instruments to improve the efficiency and equity consequences of the energy market. They can intervene in the market by using instruments such as public production units, regulation policies, taxes, and subsidies (WER, 2016; Amin, 2019).

Energy plays an essential role in an economy. As a result, it is a very crucial component in the analysis of an emerging economy like Bangladesh (Amin, 2019). In fact, energy is a vital component in growth, directly or indirectly, as a compliment to capital and labor as input factors of production (Shahbaz, 2012). Nowadays, economy has become energy dependent and Bangladesh is not apart from this. To expand the economy of Bangladesh, energy plays a very crucial role. According to the various source of energy, the energy sector of Bangladesh includes natural gas, electricity, petroleum, and coal (Islam, 2011).

Although Bangladesh is considered as a developing economy, however, the country has gained the recorded GDP growth rate which is around $8.13 \%$ in the year 2018-2019 (BBS, 2019). This was possible through the development of micro credit and garment industry. The gross domestic product (GDP) is a measurement that is used to gauge the health of an economy. Moreover, GDP is one of the primary indicators of an economy. GDP represents the aggregated money value of all goods and services over a specific time period of a nation. GDP can be used as a measure of economic growth of a country (Dey, 2019). On the other hand, real GDP is an inflation adjusted measurement. It reflects the values of all goods and services produced in a given year within a nation, which is expressed in a base year price (Amin et al., 2014; Sultanuzzaman et al., 2018).

Since insufficient power supply and energy supply is one of the major constraints in the economic growth of Bangladesh, the decision of energy policy used to play an important role in the economy of Bangladesh. Depending on the direction of causality, energy efficiency may turn out to be the most important option to manage the large unmet energy demand (Ahamad, 2011). Moreover, energy policy can be used in the development of the economy in Bangladesh. If the causality runs from energy consumption to real GDP, then conserving energy may be problematic. It would imply that as energy consumption drops, GDP and economic growth will suffer. As Bangladesh aim to become an upper middle income country by 2021, in order to determine what the right policy for Bangladesh should be, one needs to carefully examine the direction of causality between energy consumption and GDP (Amin, 2019).

On the other hand, industry sector consumes most of the energy supply in Bangladesh. Therefore, around $47.8 \%$ of the total energy consumption is done by industry sector (Uddin, 2019). Moreover, around $31.31 \%$ of total 
GDP of Bangladesh is shared by the industrial sector of Bangladesh (BBS, 2019). Several types of industries exist in the economy of Bangladesh. Here, garment and health industries are the vital ones, while industries like pharmaceutical industries, telecommunication industries, private sector industries, handicrafts industries, and production industries are functioning in Bangladesh. All these industries directly depend on energy (Moazzem, 2019). This is because Industry Value Added is directly related to the value addition of the products of industries. Also, the data which measured the actual profit earned by the industrial sector of Bangladesh were not available. As a result, in this study, Industry Value Added has been used as the indicator of industry sector. Thus, the direction of causality of Industry Value Added with energy consumption and GDP is important in making different policies that will better the economy of Bangladesh (Hussain et al., 2018).

\section{Background of the Study}

Asafu-Adjaye (2000) analyzed the relationship between energy and growth in developing Asian countries using annual time series of the variables energy consumption, GDP, and consumer price index (CPI) for the period 1971-1995 using the VECM model. The long-run cointegration relationship between energy consumption and economic growth for an investigated sample of 11 East Asian countries found a strong relation running from economic growth to energy consumption for most cases, except for Indonesia and Philippines (Aslan, 2010). Moreover, the inverse relation between two variables is observed for these two countries. Instead of using economic growth, the real GDP, including energy prices, for 25 OECD countries from 1981 to 2007 was being used to examine the long-run relationship with energy consumption and the results suggested that energy consumption is priceinelastic (Belke et al., 2011). The presence of a bi-directional causal relationship between energy consumption and economic growth was found from the causality tests. Moreover, the existence of a unidirectional causality running from per capita GDP to per capita energy consumption for Vietnam during the 1976- 2010 period was observed (Binh, 2011). The relationship between total energy consumption and real gross domestic product (GDP), covering the period between 1992 and 2010, was also explored in Croatia employing the bivariate vector autoregression (VAR) and Granger causality tests. Furthermore, the impulse response function and variance decomposition analysis were used to trace the dynamic response paths of shocks to the system. The outcome of this paper found a unidirectional causality running from total energy consumption to GDP, and an impulse response to GDP caused by energy consumption, being mainly embodied in the first year (Borozan, 2013). 
Kum (2012) examined the unit root properties of per capita energy consumption for 15 East Asia and Pacific countries from 1971-2007. In the previous year, the relationship between energy consumption and the gross domestic product in seventeen Asian countries had been studied (Lau et al., 2011).

Another study was conducted by Lee (2005) about the energy-growth relationship with the bivariate panel VAR method using multiple break analysis. Johansen's multivariate cointegration tests preceded by various unit root or non-stationarity tests for six Asian economies (India, Pakistan, Malaysia, Singapore, Indonesia and the Philippine) was studied alongside with the causal relationship between energy consumption and economic growth (Masih, 1996). Yang's model was applied to examine the impact of electricity supply on economic growth in Sri Lanka and identified that the expected increase in economic output due to increased electricity supply (parameter EO) played a crucial role in their cost benefit analysis model (Morimoto, 2004). Narayan (2005) examined the relationship between electricity consumption, employment, and real income in Australia and found that that electricity consumption, employment, and real income were cointegrated. Narayan further stated that in the long run, employment and real income Granger caused electricity consumption, while in the short run there was weak unidirectional Granger causality running from income to electricity consumption and from income to employment.

After considering many studies based on energy consumption and economy growth of several countries, this present study has been performed to address the present issue of this paper.

\section{Research Objective of the Study}

The study has been conducted to quantify the causal relationship among energy consumption, real GDP, and industry value added for Bangladesh as well as to determine the dynamic linkages among the variables. The results of the study may help the policy makers of Bangladesh to make suitable policies regarding the economy of Bangladesh according to the direction causality among the variables of the study. It will also be helpful for policy formulation regarding the developing industry sector to increase the GDP.

\section{Data and Variables}

In the present study, the time series data have been used from the World Bank Data Bank for Bangladesh from 1972 to 2014. The time series variables of the study are energy use or consumption which is measured as kilotons of oil equivalent of the final use of coal, natural gas, petroleum, electric power, and bio-fuels. The other two time series variables are Real 
GDP and Industry Value Added of Bangladesh. Thus, both of them are measured in US Dollars constant to the price of year 2005.

\section{Methodology}

In this study, the Granger Causality test has been performed to identify the short-run causal relationships among the variables of the study (Engle \& Granger, 1987). Then the cointegration test procedures have been employed to find whether the study variables are cointegrated or not. Since the results of the cointegration test procedures supported that the study variables are cointegrated, then cointegated VAR or Vector Error Correction Model (VECM) have been used to find the extent of deviation from the long-run steady state equilibrium. One of the implications of the cointegration is that if the variables are cointegrated, then there should be an error correction presentation. Thus, these error correction terms are an indicator of the longrun relationship among the variables. The estimated Vector Error Correction Model (VECM) is given as:

$$
\begin{aligned}
& \Delta \text { lnEnergyUse }=\hat{\alpha}_{0}+\sum_{i=1}^{2} \hat{\alpha}_{1 i} \Delta \ln R e a l G D P_{t-i}+\sum_{i=1}^{2} \Delta \text { lnIndustryValueAdded }{ }_{t-I} \\
& +\sum_{i=1}^{2} \hat{\alpha}_{3 i} \Delta \text { lnEnergyUse } e_{t-i}+\hat{\alpha}_{4} E C T_{1, t-1}+\hat{\alpha}_{5} E C T_{2, t-1} \\
& \Delta \text { InRealGDP }=\hat{\beta}_{0}+\sum_{i=1}^{2} \hat{\beta}_{1 \mathrm{i}} \Delta \text { InEnergyUse } \mathrm{t}_{\mathrm{t}-\mathrm{i}}+\sum_{i=1}^{2} \hat{\beta}_{2 \mathrm{i}} \Delta \text { InIndustryValueAdded } \mathrm{d}_{\mathrm{t}-\mathrm{i}} \\
& +\sum_{i=1}^{2} \hat{\beta}_{3 \mathrm{i}} \Delta \ln R e a l G D P_{\mathrm{t}-\mathrm{i}}+\hat{\beta}_{4} \mathrm{ECT}_{1, \mathrm{t}-1}+\hat{\beta}_{5} \mathrm{ECT}_{2, \mathrm{t}-1} \\
& \Delta \text { lnIndustryValueAdded }=\widehat{\Upsilon}_{0}+\sum_{i=1}^{2} \widehat{\Upsilon}_{1 \mathrm{i}} \Delta \text { lnEnergyUse } e_{\mathrm{t}-\mathrm{i}}+\sum_{i=1}^{2} \widehat{\Upsilon}_{2 \mathrm{i}} \Delta \operatorname{lnRealGDP_{\mathrm {t}-\mathrm {i}}} \\
& +\sum_{i=1}^{2} \hat{\Upsilon}_{3 \mathrm{i}} \Delta \text { InIndustryValueAdded } \mathrm{t}-\mathrm{i}+\hat{\Upsilon}_{4} \mathrm{ECT}_{1, \mathrm{t}-1}+\hat{\Upsilon}_{5} \mathrm{ECT}_{2, \mathrm{t}-1}
\end{aligned}
$$

After then, variance decompositions have been performed to measure the degree of exogeneity and endogeneity among the variables beyond the sample period. The VECM, F-test, and t-test may be interpreted as within sample causality tests. They can indicate only the Granger exogeneity or endogeneity of the dependent variable within the sample period. VDCs may be termed as out-of-sample causality tests, by partitioning the variance of the forecast error of a certain variable (say, energy consumption) into proportions attributable to innovations (or shocks) in each variable in the system including its own. Therefore, this can provide an indication of these relativities. A variable that is optimally forecast from its own lagged values will have its forecast error variance accounted for by its own disturbances (Sims, 1972).

The information contained in the variance decompositions are equivalently represented by impulse response functions in the study. An IRF measures the effect of a shock to an endogenous variable on itself or on another endogenous variable. In IRF, if there is a reaction of one variable to an impulse in another variable, then the latter can be called causal for the former. It essentially maps out the dynamic response path of a variable (say, real GDP) due to one-period standard deviation shock to another variable (say, energy consumption) (Masih, 1997). 


\section{Results and Discussion}

In this study, the Augmented Dickey-Fuller test and Philips-Perron test are employed to check the stationarity of the time series variables. Both tests are used at first on the level and then on the first difference of the time series at 5\% level of significance (Dickey \& Fuller, 1981; Phillips \& Perron, 1988). Table 1 shows the overall results of the time series variables.

Table 1. Result of the unit root test of the time series variables

\begin{tabular}{|l|ll|lc|}
\hline & \multicolumn{2}{|c|}{ Level } & \multicolumn{2}{c|}{ First Difference } \\
\hline Variables & ADF Test & P-P Test & ADF Test & P-P test \\
& Statistic $\tau(\mathrm{P})$ & Statistic z(t) & Statistic $\tau(\mathrm{D})$ & Statistic z(t) \\
\hline lnEnergyUse & -0.4 & 0.075 & $-4.676^{*}$ & $-11.484^{*}$ \\
& {$[0.9869]$} & {$[0.8767]$} & {$[0.0008]$} & {$[0.0000]$} \\
& & & & \\
InRealGDP & -0.414 & 0.304 & $-5.085^{*}$ & $-11.063^{*}$ \\
& {$[0.9864]$} & {$[0.9963]$} & {$[0.0001]$} & {$[0.0000]$} \\
& & & & \\
lnIndustryValueAdded & -0.257 & -1.415 & $-4.232^{*}$ & $-13.264^{*}$ \\
& {$[0.9904]$} & {$[0.57573]$} & {$[0.0040]$} & {$[0.0000]$} \\
\hline
\end{tabular}

Note: * indicates significance at 5\% level and the parenthesis indicates the p-value of the test statistic. (STATA has been used to estimate these model.)

The following table represents the results of selecting the appropriate lag orders of the VEC model. It has been found that AIC, HQIC, and SBIC have a minimum criteria at lag 2 and only FPE is minimum at lag 3. So, the selected order of lag is 2 . In this study, the annual time series data have been used and the VEC model with 2 lagged values are considered.

Table 2. Lag order selection criterion

\begin{tabular}{|c|c|c|c|c|c|c|c|}
\hline Lags & LL & LR & DF & FPE & AIC & HQIC & SBIC \\
\hline 0 & 116.877 & & 9 & $3.6 \mathrm{e}-07$ & -6.326 & -6.28 & -6.19 \\
\hline 1 & 276.923 & 320.09 & 9 & $8.2 \mathrm{e}-11$ & -14.718 & -14.53 & -14.19 \\
\hline 2 & 303.82 & 53.793 & 9 & $3.1 \mathrm{e}-11$ & $-16.054^{*}$ & $-15.59^{*}$ & $-14.79^{*}$ \\
\hline 3 & 318.97 & 30.3 & 9 & $2.2 \mathrm{e}-11^{*}$ & -15.71 & -15.39 & -14.73 \\
\hline 4 & 327.632 & $17.324^{*}$ & 9 & $2.4 \mathrm{e}-11$ & -16.04 & -15.44 & -14.32 \\
\hline
\end{tabular}

Subsequently, the Johansen Cointegration test is applied to test whether there is any cointegrating relationship among the variables of the study. Both the trace and eigenvalue test statistics are used to determine the long run relationship (Johansen, 1988). Table 3 shows the results of the trace statistic and maximum eigenvalues test statistic of cointegrating relationship among the variables.

Table 3. Johansen cointegration test for determining cointegrating relationship

\begin{tabular}{|c|c|c|c|c|c|c|c|c|}
\hline Trace Test & \multicolumn{8}{|c|}{ Maximum Eigenvalue Test } \\
\hline $\begin{array}{l}\text { Maximum } \\
\text { rank }\end{array}$ & Eigenvalues & $\mathrm{J}_{\text {trace }}$ & $\begin{array}{l}5 \% \\
\mathrm{CR}\end{array}$ & $\begin{array}{l}1 \% \\
\mathrm{CR}\end{array}$ & $\mathrm{H}_{\mathrm{o}}$ & $\mathrm{J}_{\max }$ & $\begin{array}{l}5 \% \\
\text { CR }\end{array}$ & $\begin{array}{l}1 \% \\
\mathrm{CR}\end{array}$ \\
\hline$r=0$ & & 92.8684 & 29.68 & 35.65 & $r=0$ & 47.5309 & 20.97 & 25.52 \\
\hline
\end{tabular}




\begin{tabular}{|c|c|c|c|c|c|c|c|c|}
\hline $\mathrm{r} \leq 1$ & 0.71373 & 45.3375 & 15.41 & 20.04 & $\mathrm{r}=1$ & 44.2954 & 14.07 & 18.63 \\
\hline $\mathrm{r} \leq 2$ & 0.68829 & $1.0421^{*}$ & 3.76 & 6.65 & $\mathrm{r}=2$ & $1.0421^{*}$ & 3.76 & 6.65 \\
\hline $\mathrm{r} \leq 3$ & 0.02705 & & & & $\mathrm{r}=3$ & & & \\
\hline
\end{tabular}

Note: * indicates significance at 5\% level and CR means critical region.

From the table above, it can be observed that for both of the tests, the null hypothesis of at most two cointegrating relationships among the variables are accepted. So, it can be concluded that there exists two cointegrating relationships which implies that there exists two cointegrating linear combinations which are stationary. Also, it can be said that the variables share long-run equilibrium relationship among them. Now to find the dynamic linkages between them, the Granger causality tests are conducted under the VECM to test inter temporal causality among the variables which are considered in the study.

Since the variables are cointegrated, the deviations from the equilibrium will respond to the changes in the dependent variable in order to force movements towards long-run equilibrium in the short run. So, Granger causality has been performed to determine the short-run causal relationships among the variables. Moreover, VEC model has been used to find the longrun causal relationships among the variables which can cause deviation from the long-run equilibrium. That is why Granger causality under VEC model has been applied. Thus, the following table shows summary of the results where the short-run causal relationships are indicated by the Wald test of the differenced variables, while the long-run relationships are indicated by the significant error correction term.

Table 4. Granger causality test results under VECM

\begin{tabular}{|l|lcccl|}
\hline & \multicolumn{5}{|c|}{ Differenced Variables } \\
\hline & $\Delta \ln E U$ & $\Delta \operatorname{lnRG}$ & $\Delta \ln I n d$ & ECT1,t-1 & ECT2,t-1 \\
\hline$\Delta \ln E U$ & & 0.60 & 1.17 & -0.4682487 & -0.100553 \\
& & {$[0.7403]$} & {$[0.5583]$} & {$\left[0.030^{*}\right]$} & {$\left[0.084^{* * *}\right]$} \\
\hline$\Delta \ln R G$ & 4.98 & & 4.39 & 0.3861564 & 0.1146598 \\
& {$\left[0.0828^{* * *}\right]$} & & {$[0.1113]$} & {$[0.000]$} & {$[0.000]$} \\
\hline$\Delta \operatorname{lnd}$ & 1.61 & 9.21 & & 0.9229229 & 0.2236672 \\
& {$[0.4463]$} & {$[0.0100]$} & & {$[0.002]$} & {$[0.006]$} \\
\hline
\end{tabular}

\section{Note:}

* indicates significance at $5 \%$ level

** indicates significance at $1 \%$ level

$* * *$ indicates significance at $10 \%$ level

$\mathrm{P}$-value is indicated in the brackets.

$\mathrm{ECT}_{1, \mathrm{t}-1}$ and $\mathrm{ECT}_{2, \mathrm{t}-1}$ indicate the first and second error correction terms respectively.

$\Delta$ indicates the differenced value of the variables

$\operatorname{lnEU}=$ Natural $\log$ of Energy Use, $\ln R G=$ Natural Log of Real GDP and lnInd $=$ Natural $\log$ of

Industry Value Added 
From the pair-wise Granger causality test, it is clear that there is a unidirectional causal relation running from Real GDP to Energy consumption or Energy Use for Bangladesh. On the other hand, there exists another unidirectional causal relationship running from Industry Value Added to Real GDP. Besides these, there is no short-run causal relationship between any pair of variables. From the above table, it can also be observed that Real GDP is the least exogenous variables among the variables which are being considered in the study, while Energy Consumption or Energy Use is the most exogenous variable among them.

In the study, two cointegrating relations among the variables have been found. As a result, two correction terms and two cointegrating vectors exist. The Vector Error Correction Model (VECM) is then applied to find the longrun relationship among the variables and when there is a deviation from the equilibrium cointegrating relationship measured by the error correction term adjust to clear the disequilibrium. However, this implies that it bears the shortrun adjustment to the long-run steady state. Now the long-run cointegrating equations are given with their corresponding t-statistics which is given in the parenthesis:

$$
\begin{aligned}
& \text { lnEn } \widehat{\text { ergy }} \text { Use }=-10.65371+0.6086543(6.21,0.000) \ln R e a l G D P+0.2397898 \\
& \text { (3.66, 0.001) InIndustryValueAdded } \\
& \ln \widehat{\text { ealG }} D P=13.43117+0.8390461(6.21,0.000) \text { lnEnergyUse }+0.1242985 \\
& (1.42,0.164) \text { InIndustryValuedAdded } \\
& \text { InIndustryValuedAdded }=2.00286+1.106837 \text { (3.66, 0.001)lnEnergyUse } \\
& +0.4162015(1.42,0.164) \ln R e a l G D P
\end{aligned}
$$

In the first equation, where Energy Consumption or Energy Use is the dependent variable, all the coefficients of the long-run relationship are significant at $1 \%$ level of significance (t-statistics and $\mathrm{P}$-values are given in the parenthesis). This result suggested that an increase in the Real GDP and Industry Value Added have a positive impact on the change in Energy Consumption and Energy Use of Bangladesh, keeping all other variables at a fixed level. In the second equation, where Real GDP is the dependent variable, only the coefficient of the independent variable Energy Consumption or Energy Use is significant at $1 \%$ level of significance. On the other hand, the coefficient of the independent variable Industry Value Added is insignificant even at $10 \%$ level of significance. Similarly, in the third equation, where Industry Value Added is the dependent variable, only the coefficient of the independent variable, Energy Consumption or Energy Use is significant at $1 \%$ level of significance, while the coefficient of the independent variable and Real GDP is insignificant even at $10 \%$ level of significance. 
Thus it can be stated that in the Granger causality under the VECM, there has been found only two unidirectional causal relationships running from Real GDP to Energy Consumption or Energy Use and another unidirectional causal effect of Industry Valued Added on the Real GDP. The results of VECM suggest that a long-run relationships exists among all of the variables under study. This means that although the short-run Energy consumption or Energy Use does not seem to be significantly affected by Real GDP and Industry Value Added, the results suggest that a long-run relationship exist between them. Similarly, Industry Value Added has a short-run causal effect only with the Real GDP. However, in the long-run, it is related to both the Real GDP and the Energy Consumption or Energy Use.

In order to measure the relative strength of these results based on the causality tests, the system is now shocked and has partitioned the forecast error variance of each of the variables (Sims, 1972). The decompositions are presented in the following table based on the ordering of the VECM. Thus, this means the result is presented in the ordering of the variables [Energy Use, Real GDP, and Industry Value Added].

Table 5. Results of the Forecasts Error Variance Decomposition

\begin{tabular}{|c|c|c|c|c|c|c|c|c|c|}
\hline \multirow[b]{3}{*}{ Years } & \multicolumn{9}{|c|}{ Percentage of forecast variance explained by innovations in } \\
\hline & \multicolumn{3}{|c|}{$\begin{array}{l}\text { Relative variance of } \\
\Delta \text { EnergyUse }\end{array}$} & \multicolumn{3}{|c|}{$\begin{array}{c}\text { Relative variance of } \\
\Delta \text { RealGDP }\end{array}$} & \multicolumn{3}{|c|}{$\begin{array}{c}\text { Relative variance of } \\
\Delta \operatorname{lnIndustryValueAdded}\end{array}$} \\
\hline & 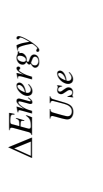 & 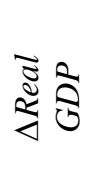 & 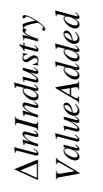 & $\begin{array}{l}\overrightarrow{0} \\
\frac{1}{2} \\
\frac{1}{2}\end{array}$ & 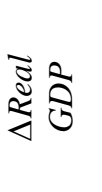 & 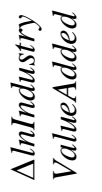 & $\underset{\Downarrow}{\vec{j}} \stackrel{\vec{y}}{\forall}$ & 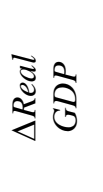 & 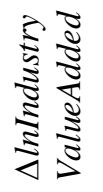 \\
\hline 1 & 1.00 & 0.00 & 0.00 & 0.90 & 99.10 & 0.00 & 13.91 & 37.77 & 48.31 \\
\hline 2 & 96.70 & 0.08 & 3.22 & 1.42 & 88.72 & 9.86 & 34.20 & 31.80 & 34.00 \\
\hline 3 & 94.24 & 1.76 & 4.00 & 3.33 & 73.90 & 22.77 & 43.77 & 27.18 & 29.06 \\
\hline 4 & 94.53 & 1.40 & 4.07 & 3.06 & 72.17 & 24.77 & 50.02 & 24.23 & 25.75 \\
\hline 5 & 94.96 & 1.27 & 3.76 & 3.26 & 72.50 & 24.25 & 53.45 & 22.86 & 23.69 \\
\hline 6 & 94.95 & 1.13 & 3.92 & 3.32 & 70.53 & 26.15 & 57.86 & 21.03 & 21.11 \\
\hline 7 & 94.90 & 1.15 & 3.95 & 3.56 & 68.44 & 27.99 & 61.57 & 19.24 & 19.18 \\
\hline 8 & 94.97 & 1.07 & 3.96 & 3.68 & 67.41 & 29.01 & 64.41 & 17.97 & 17.62 \\
\hline 9 & 95.05 & 1.04 & 3.91 & 3.68 & 66.78 & 29.55 & 66.65 & 17.01 & 16.34 \\
\hline 10 & 95.08 & 1.00 & 3.92 & 3.74 & 65.97 & 30.29 & 68.71 & 16.14 & 15.16 \\
\hline
\end{tabular}

From the above table, it can be observed that in the case of Bangladesh after 10-years of horizon, the results suggest that Energy Consumption or Energy use play exogenous role with almost all of its innovations explaining with its own shocks which is almost 95\%. On the other hand, the result of variance decomposition of Industry Value Added implies the relative 
endogeneity of it compared to Energy Consumption or Energy Use in Bangladesh.

The information contained in the Variance Decomposition can be equivalently represented by Impulse Response Function (IRF). IRFs essentially map out the dynamic response path of a variable (say, Real GDP) due to a one-period standard deviation shock to another variable (Masih, 1997). The graphical examination of plotting out the response paths to the various shocks to the system is given below:

Figure 1. Findings from Impulse Response Function
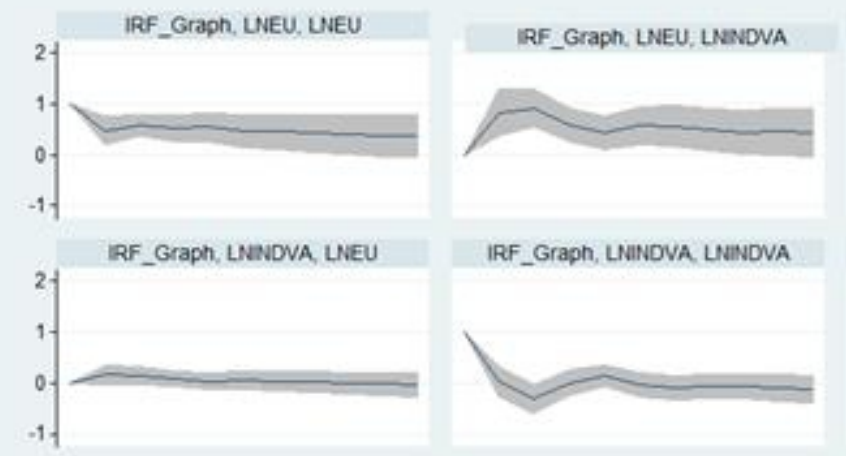

IRF_Graph, LNEU, LNRG
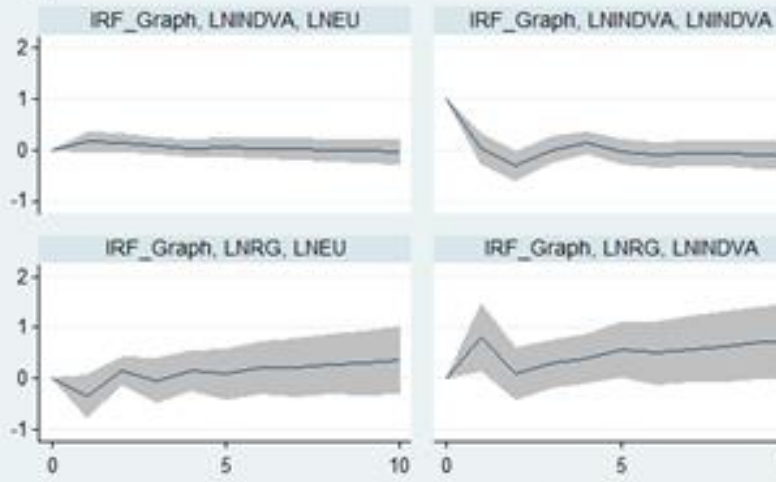

IRF_Graph, LNINDNA. LNRG

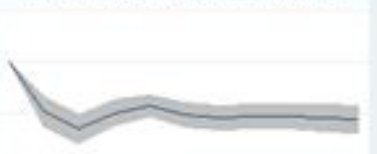

IRF_Graph, LNRG, UNEDVA

IRF_Graph, UNRG, UNRG
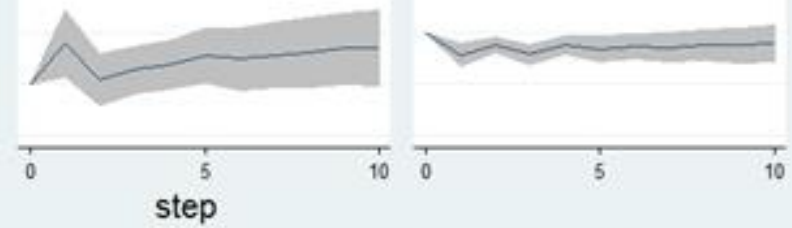

$95 \% \mathrm{Cl}$

impulse response function (irf)

Graphs by irfname, impulse variable, and response variable

\section{Conclusion}

Given the generality of the techniques involved, results for Bangladesh seem to indicate that all variables are jointly interactive in the considered causal chain. That is, the present study has been investigated to find the shortrun and the long-run relationships among Energy Consumption or Energy Use, Real GDP, and Industry Value Added. In theory, small and resource limited economies are expected to be more vulnerable to energy shocks than energysufficient economies. According to VECM analysis, it has been found that there exists a long-run relationship among the three variables, namely: Energy Consumption or Energy Use, Real GDP, and Industry Value Added. This is because all the error correction terms have been found to be significant. Although the short-run relationships have not been found significant for all 
possible pairs of variables being considered, the long-run relationships have shown significant.

The dynamic Granger causality has been conducted under the VECM in this study. According to its result, there exists a unidirectional causality running from Real GDP to Energy Consumption or Energy Use. That is, Real GDP Granger causes Energy Consumption or Energy Use. The reverse causality, that is, Energy Consumption or Energy Use Granger causes Real GDP is not significant even at $10 \%$ level of significance. The result is similar to the result one of the previous study. In that study, such type of unidirectional causal relationship that is a unidirectional causality running from GDP to electricity consumption has been found for Bangladesh (Majumder, 2007). Although the present study used the aggregated data for the variable of Energy Consumption or Energy Use, the findings of the study supported the previous mentioned study.

Since in this study a unidirectional causality has been found from Real GDP to Energy Consumption or Energy Use for Bangladesh and not vice versa, then, a well-designed energy conservation policy can play an effective role in managing the energy sector.

On the other hand, another unidirectional causality came out from Industry Value Added to Real GDP. This means that if Industry Value Added increases, then Real GDP also increases. Thus, Industry Value Added has a significant impact on Real GDP. Favorable infrastructure and a well-designed and time-befitting industrialization can develop the industrial sector of Bangladesh. Moreover, Government should take necessary steps to make Industry Value Added a stable condition. As a result, GDP will be increased to a great extent thereby making the economy of Bangladesh better.

Moreover, from the results of the VECM, it can be said that only Energy Consumption or Energy Use can be clearly declared as the exogenous variable. Also, Industry Value Added plays the role of endogenous variable. All of the findings that have been explored so far are also supported by the variance decomposition analysis and impulse response function technique.

The policy implications of the dynamic analysis of the study are quite clear. The study is an attempt to put the analysis of Energy Consumption or Energy Use, Real GDP, and Industry Value Added in a temporal Grangercausal framework. This is for the case of energy-dependent emerging economy like Bangladesh by binding the relationship among the three variables being considered within a multivariate cointegrated system. The evidence of cointegration rules out the possibility of the estimated relationship being "spurious". Therefore, this implies that Granger causality must exist in at least one direction and between a pair of variables. This, itself, is a very important and valuable finding to facilitate the task of macroeconomic forecasts and policy analysis. 
The direction of Granger causality (both short and long term) is brought to light by the Vector Error Correction Model. Moreover, Variance Decompositions and Impulse Response Functions shed light on the relative endogeneity of the variables. The present study is an academic exercise. So, one can proceed for further studies by using the concept as well as the results of the present study.

\section{References:}

1. Ahamad, M.G. \& Islam, A.K.M.N. (2011). Electricity consumption and economic growth nexus in Bangladesh: revisited evidences. Energy Policy, 39(10), 6145-6150.

2. Alam, M.J., Begum, I.A., Buysee, J., \& Huylenbroeck, G.V. (2012). Energy consumption, carbon emissions and economic growth nexus in Bangladesh: co-integration and dynamic causality analysis. Energy Policy, 45(C), 217-225.

3. Amin, M.M.A. (2019). An Evidence-Based Possible Framework for Addressing Economic and Health Challenges of the Ageing Population in Bangladesh. European Scientific Journal, 15(3), 1-14.

4. Amin, M.M.A., Rana, S. M., \& Kalam, I. M. S. (2017). Population movements towards Dhaka: Disquiets and Commendations. European Scientific Journal, 13(5), 402-415.

5. Amin, M.M.A., Sajib, A.H., \& Alamgir, M. (2014). Investigating Causal Relations of Economic Variables: Capital, GDP, Labour and Population in Sweden (1870-2000). Dhaka University Journal of Science, Dhaka University, 62(2), 81-86.

6. Amin, S.B. \& Khan, F. (2019). Modelling Energy Demand in Bangladesh: An Empirical Analysis. The Journal of Developing Areas, 54(1), 39-52.

7. Amin, S.B. \& Rahman, S. (2019). Importance of Energy Efficiency in Bangladesh. Springer, Cham, 15-19.

8. Asafu-Adjaye, J. (2000). The relationship between energy consumption, energy prices and economic growth: time series evidence from Asian developing countries. Energy Economics,22(6),615-625.

9. Aslan, A. \& Kum, H. (2010). An investigation of cointegration between energy consumption and economic growth: Dynamic evidence from East Asian countries. Global Economic Review, 39(4), 431-439.

10. BBS (2019). Provision+al estimates of Gross Domestic Product (GDP) of Bangladesh 2018-19(p), Bangladesh Bureau of Statistics, 2018-19(p). 
11. Belke, A., Dobnik, F., \& Dreger C. (2011). Energy consumption and economic growth: New insights into the cointegration relationship.Energy Economics, 33(5), 782-789.

12. Binh, P.T. (2011). Energy Consumption and Economic growth inVietnam: Threshold Cointegration and Causality Analysis. International Journal of Energy Economics and Policy, 1(1), 1-17.

13. Borozan, D. (2013). Exploring the relationship between energy consumption and GDP: Evidence from Croatia. Energy Policy, Elsevier,59(C), 373-38.

14. Cutler, J.C. \& Christopher, M. (2006). Dictionary of energy. Amsterdam: Elsevier.

15. Dey, S. (2019). Electricity consumption and income nexus: evidence from Bangladesh. International Journal of Energy Sector Management, 13(4), 1020-1037.

16. Dickey, D. \& Fuller, W. (1981). Likelihood Ratio Statistics for Autoregressive Time Series with a Unit Root. Econometrica, 49(4), pp. 1057-1072.

17. Engle, R. \& Granger, C. (1987). Co-Integration and Error Correction: Representation, Estimation, and Testing. Econometrica, 55(2), 251276.

18. Greene, W. (2002). Econometric Analysis. Prentice Hall, New Jersey.

19. Hussain, Z., Zhang, F., Khan, NS., Alam, A., \& Shahriar, S. (2018). Bangladesh Development Update: Powering the Economy Efficiently (English). Washington, D.C.: World Bank Group.

20. Islam, MS. (2011), Research Report: Energy Sector of Bangladesh, IDLCFinance Limited, Bangladesh.

21. Johansen, S. (1988). Statistical analysis of cointegration vectors. Journal of Economic Dynamics and Control, 12(2-3), 231-254.

22. Kraft, J. \& Kraft, A. (1978). On the Relationship between Energy and GNP. Journal of Energy and Development, 3, 401-403.

23. Kum, H. (2012). Are Fluctuations in Energy Consumption Transitory or Permanent? Evidence from a Panel of East Asia \& Pacific Countries. International Journal of Energy Economics and Policy, 2(3), 92-96.

24. Lau, E., Chey, X.H., \& Choong, C.K. (2011). Energy-Growth Causality: ASIAN Countries Revisited. International Journal of Energy Economics and Policy, 1(4), 140-149.

25. Lee, C.C. (2005). Energy consumption and gdp in developing countries: A cointegrated panel analysis. Energy Economics, 27(3), 415-427. 
26. Majumder, P. \& Marathe, A. (2007). Causality relationship between electricity consumption and GDP in Bangladesh. Energy Policy,35(1), 395-402.

27. Masih, A.M.M. \& Masih, R. (1996). Energy consumption, real income and temporal causality: results from a multi-country study based on cointegration and error-correction modelling techniques. Energy Economics, 18(3), 165-183.

28. Masih, A.M.M. \& Masih, R. (1997). On the temporal causal relationship between energy consumption, real income and prices; some new evidence from Asian energy dependent NICs based on a multivariate cointegration/vector error correction approach. Journal of Policy Modeling, 19 (4), 417-440.

29. Moazzem, KG. \& Ali, M. (2019). The Power and Energy Sector of Bangladesh: Challenges of Moving beyond the Transition Stage. Centre for Policy Dialogue (CPD), Bangladesh.

30. Morimoto, R. \& Hope, C. (2004). The impact of electricity supply on economic growth in Sri Lanka. Energy Economics, 26(1), 77-85.

31. Narayan, P. \& Smyth, R. (2005). Electricity consumption, employment and real income in Australia evidence from multivariate Granger causality tests. Energy Policy, 33(9), 1109-1116.

32. Phillips, P. \& Perron, P. (1988). Testing for a Unit Root in Time Series Regression. Biometrica, 75(2), 335-346.

33. Shahbaz, M. \& Lean, H.H. (2012).The dynamics of electricity consumption and economic growth: a revisit study of their causality in Pakistan. Energy, 39(1), 146-153.

34. Sims, C. (1972). Money, income and causality. The American Economic Review, 62(4), 540-552.

35. Sultanuzzaman, MR., Hongzhong, F., Banban, W., Miraj, AB., \& Adnan, KMM. (2018). Trade (exports) as an opportunity for Bangladesh: A VECM analysis. The International Trade Journal, 1-16.

36. Uddin, M.M. (2019). Promoting private sector investment through large scale adoption of energy saving technologies and equipment for garment sector of Bangladesh. IDCOL, Bangladesh.

37. WER (2016). World Energy Resources, World Energy Council, United Kingdom. 